\title{
Psychological Well-Being Revisited: Advances in the Science and Practice of Eudaimonia
}

\author{
Carol D. Ryff \\ University of Wisconsin-Madison, Madison, Wisc., USA
}

\author{
Key Words \\ Well-being · Eudaimonia · Aging · Development · Health · \\ Biomarkers · Neuroscience $\cdot$ Practice
}

\begin{abstract}
This article reviews research and interventions that have grown up around a model of psychological well-being generated more than two decades ago to address neglected aspects of positive functioning such as purposeful engagement in life, realization of personal talents and capacities, and enlightened self-knowledge. The conceptual origins of this formulation are revisited and scientific products emerging from 6 thematic areas are examined: (1) how well-being changes across adult development and later life; (2) what are the personality correlates of well-being; (3) how well-being is linked with experiences in family life; (4) how well-being relates to work and other community activities; (5) what are the connections between well-being and health, including biological risk factors, and (6) via clinical and intervention studies, how psychological well-being can be promoted for ever-greater segments of society. Together, these topics illustrate flourishing interest across diverse scientific disciplines in understanding adults as striving, meaning-making, proactive organisms who are actively negotiating the challenges of life. A take-home message is that increasing evidence supports the health protective features of psychological well-being in reducing risk for disease and promoting length of life. A recurrent and increasingly important theme
\end{abstract}

is resilience - the capacity to maintain or regain well-being in the face of adversity. Implications for future research and practice are considered.

(c) 2013 S. Karger AG, Basel

\section{Introduction}

Nearly 25 years ago a model of psychological well-being was put forth by Ryff [1] to address omissions in formulations of positive human functioning that prevailed in the 1980s. Implications of the formulation for psychotherapy and psychosomatics were subsequently considered [2]. This article examines what has been learned from the extensive research that proliferated around this model of well-being, particularly as it relates to health (mental and physical) and interventions intended to improve the human condition. Before reviewing scientific advances, the philosophical and theoretical foundations of the formulation are revisited to underscore its distinctiveness vis-à-vis alternative approaches to well-being. Issues of measurement are also considered in this opening section.

\section{Conceptual Foundations and Empirical Indicators}

Although considerable empirical research in the 1980s was concerned with well-being - as studied in national surveys $[3,4]$ and segments of psychology $[5,6]-$ such 


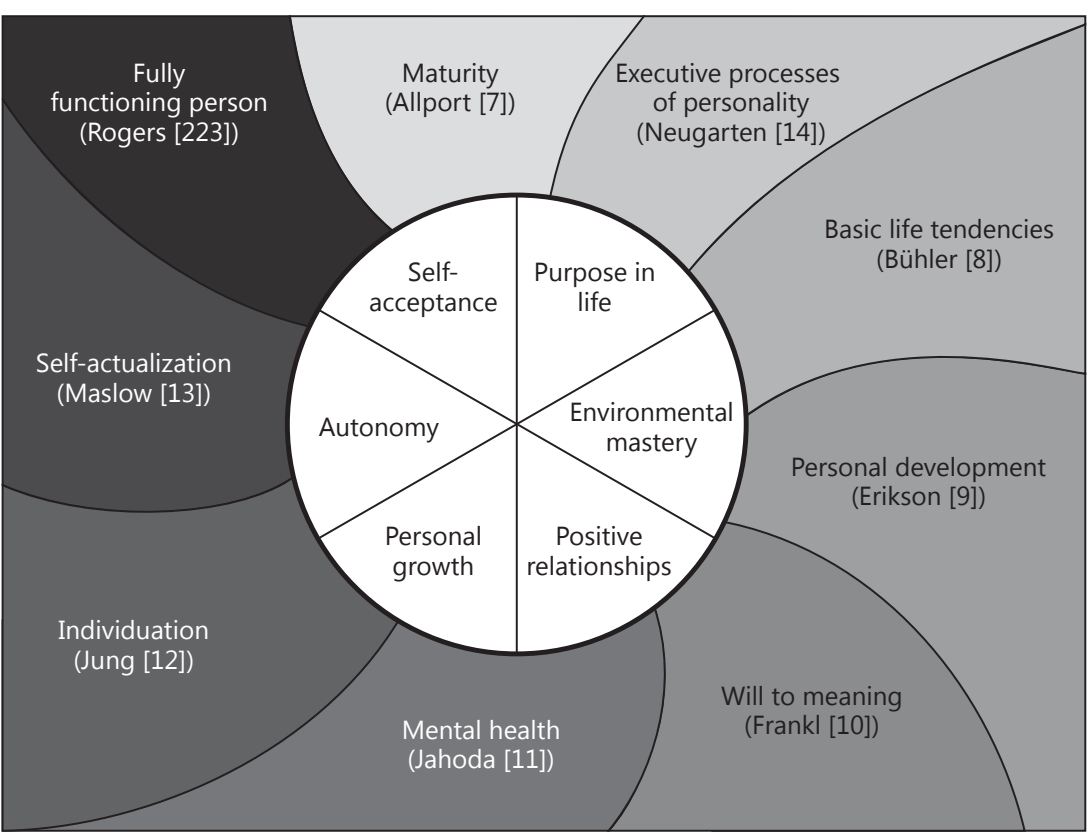

Fig. 1. Core dimensions of psychological wellbeing and their theoretical foundations.

endeavors focused largely on reports of happiness, life satisfaction and positive affect. Minimal attention was given to the deeper question, namely, what constitutes essential features of well-being? The neglect was puzzling, given the deep philosophical roots of happiness dating back to the ancient Greeks along with the pervasive interest shown in humanistic, existential, developmental and clinical psychology in distilling positive human functioning [7-14]. These differing conceptions revealed overlapping themes in articulating what it means to be self-actualized, individuated, fully functioning or optimally developed. Such points of convergence became the basis for distilling 6 key components of well-being (see fig. 1). Following the construct-oriented approach to personality assessment [15], definitions of high and low scorers were then generated for each dimension, and self-report items were written to operationalize the definitions.

The new measures probed the following dimensions: (1) the extent to which respondents felt their lives had meaning, purpose and direction (purpose in life); (2) whether they viewed themselves to be living in accord with their own personal convictions (autonomy); (3) the extent to which they were making use of their personal talents and potential (personal growth); (4) how well they were managing their life situations (environmental mastery); (5) the depth of connection they had in ties with significant others (positive relationships), and (6) the knowledge and acceptance they had of themselves, in- cluding awareness of personal limitations (self-acceptance). Detailed definitions are provided in table 1. Taken together, these dimensions offered a notable contrast to extant indicators focused on feeling good, happy, positive or satisfied with life. A decade later these contrasting approaches were framed as fundamental distinctions in scientific research on well-being [16] - that is, while early studies reflected a largely hedonic approach, the above indicators were consistent with a eudaimonic perspective. Both terms were traceable to the ancient Greeks.

Indeed, the deeper philosophical roots of the new model of well-being resided in Aristotle's formulation of the highest human good, which in his Nichomachean Ethics [17] he termed eudaimonia. His writings sharpened the significance of this alternative approach to well-being [18] via the claim that the highest of all human goods is not happiness, feeling good or satisfying appetites. Instead, it is about activities of the soul that are in accord with virtue, which Aristotle elaborated to mean striving to achieve the best that is within us. Eudaimonia thus captured the essence of the two great Greek imperatives: first, to know yourself, and second, to become what you are. The latter requires discerning one's unique talents (the daimon that resides in us all), and then working to bring them to reality. Two centuries later, these ideas flowed naturally into humanistic and developmental conceptions of self-realization. Existential thinking, in turn, emphasized the importance of finding meaning in adversity 
Table 1. Definitions of theory-guided dimensions of well-being

\section{Autonomy}

High scorer Is self-determining and independent; able to resist social pressures to think and act in certain ways; regulates behavior from within; evaluates self by personal standards

Low scorer Is concerned about the expectations and evaluations of others; relies on judgments of others to make important decisions; conforms to social pressures to think and act in certain ways

\section{Environmental mastery}

High scorer Has a sense of mastery and competence in managing the environment; controls complex array of external activities; makes effective use of surrounding opportunities; able to choose or create contexts suitable to personal needs and values

Low scorer Has difficulty managing everyday affairs; feels unable to change or improve surrounding context; is unaware of surrounding opportunities; lacks sense of control over external world

Personal growth

High scorer Has a feeling of continued development; sees self as growing and expanding; is open to new experiences; has sense of realizing his or her potential; sees improvement in self and behavior over time; is changing in ways that reflect more self-knowledge and effectiveness

Low scorer Has a sense of personal stagnation; lacks sense of improvement or expansion over time; feels bored and uninterested with life; feels unable to develop new attitudes or behaviors

Positive relations with others

High scorer Has warm, satisfying, trusting relationships with others; is concerned about the welfare of others; capable of strong empathy, affection and intimacy; understands give and take of human relationships

Low scorer Has few close, trusting relationships with others; finds it difficult to be warm, open, concerned about others; is isolated and frustrated in interpersonal relationships; not willing to make compromises to sustain important ties with others

Purpose in life

High scorer Has goals in life and a sense of directedness; feels there is meaning to present and past life; holds beliefs that give life purpose; has aims and objectives for living

Low scorer Lacks a sense of meaning in life; has few goals or aims, lacks sense of direction; does not see purpose in past life; has no outlooks or beliefs that give life meaning

Self-acceptance

High scorer Possesses a positive attitude toward the self; acknowledges and accepts multiple aspects of self, including good and bad qualities; feels positive about past life

Low scorer Feels dissatisfied with self; is disappointed with what has occurred in past life; is troubled about certain personal qualities; wishes to be different than what he or she is

or an absurd world. From the scientific perspective, the larger point was that research on well-being, if it is to do justice to the topic, needs to encompass the meaningmaking, self-realizing, striving aspects of being human.

Philosophical gravitas counts for little, however, if key constructs are not quantified. The development of assessment tools, essential for empirical research, shifted the focus to questions of psychometric properties. To date, more than 25 publications have evaluated the foundational evidence of scale reliability and validity [1], with a primary focus on whether the empirical facts support a 6 -factor model. Numerous studies in different cultural contexts suggest that it does [18-27]. Contrary evidence has also been provided [28-30], with accompanying critiques that the 6 dimensions are insufficiently distinct after adjusting for measurement error, and that the items are insufficiently discriminating at high levels of well-being. Others challenged these same critiques, showing that inconsistent findings on the latent structure are probably due to the use of overly short scales rather than problems with the theoretical model itself [21]. Longitudinal analyses have added to the evidence of distinctiveness among dimensions by showing differential profiles of change with age [31].

The issue of scale length has been of interest. The initial measurement scales [1] were based on 20 items for each of the 6 dimensions (120 items in total). Such length was needed to follow good scale construction guidelines (e.g. incorporate both positively and negatively phrased items) as well as to capture the multiple components of scale definitions derived from the conceptual sources described above. These parent scales were subsequently re- 
duced to 14 -item scales ( 84 items in total) to reduce respondent burden in completing the inventory $[32,33]$. A more extreme reduction in length (3 items per scale, 21 items in total) was implemented to bring the measures into a national survey study [23]. That extremely pareddown version supported the 6-factor model of well-being in a large national sample, but psychometric problems with the individual scales (low alpha coefficients) made clear the reduction had been excessive. That was because items for the ultra-short version were not selected to maximize internal consistency but rather to cover the underlying components of each scale (thereby maintaining fidelity with the conceptual foundation of each scale). What was learned in this process is the need to achieve balance between concerns about scale length (i.e. respondent burden) and goals of adequate depth of measurement to insure credible assessment of the 6 well-being constructs. Most recently, a 7-item version (42 items in total) employed in a longitudinal follow-up of the US national sample seems to achieve such balance [34].

Taking all of the above into account, the 6 scales of well-being from the original model [1] have withstood extensive psychometric scrutiny. While debates about factorial structure may continue, such concerns have not hindered the use of the scales by the larger scientific community, where still further evidence (see below) has been amassed regarding the distinctiveness across the measures (as outcomes, as antecedent influences and as moderating variables). Issues of scale length have received extensive scrutiny, with growing evidence supporting the use of 14-item, or at minimum 7-item, scales to insure quality assessment of the constructs. It is also worth noting that clinimetric criteria have been advanced to evaluate the sensitivity of the scales in revealing psychological change following clinical treatments [35-37]. In such intervention contexts (detailed below), an interview-based version of the well-being model is also available [38]. Finally, as efforts to adjudicate the measurement or clinical effectiveness of the scales have proceeded, the instruments have been translated into more than 30 different languages, thus underscoring their growing presence in science and practice around the world.

\section{Scientific Advances in Psychological Well-Being}

To date, over 350 publications using the eudaimonic scales of well-being have appeared in more than 150 scientific journals. The usage covers diverse topics extending across multiple scientific disciplines. It is beyond the scope of this article to examine the products in comprehensive detail, although illustrative categories of findings can be distilled. What follows organizes the scientific output according to 6 thematic areas: (1) development and aging; (2) personality correlates; (3) family experiences; (4) work and other life engagements; (5) health and biological research, and (6) clinical and intervention studies. Well-being is often investigated as outcome or dependent variable in these studies, but occasionally it is studied as an antecedent or predictor variable. Increasingly, it is also considered as a moderating influence (protective factor). These diverse applications underscore the broad utility of well-being constructs in contemporary scientific research. Although the last 2 thematic areas are of primary interest, the first 4 provide important evidence as to why eudaimonic well-being may be consequential for health and well-being - namely, because it is fundamentally anchored in how individuals negotiate their way through the challenges of life. This recognition further explicates why eudaimonic well-being is a worthy and essential target in intervention studies.

\section{Development and Aging}

Many researchers have used the scales to investigate adult development and psychological aging. Multiple studies have linked Erikson's [9] stages of identity formation [39], generativity [40-42] and ego integrity [43, 44] to psychological well-being. Across these endeavors, those reporting higher levels of ego development tend to show higher well-being. There are exceptions: identifying oneself as lesbian, gay or bisexual has been associated with lower eudaimonic well-being [45], with such patterns linked to experiences of discrimination. Having a more developed feminist identity, however, has been linked with higher well-being [46].

Other work has focused on themes of personal growth, extracted from autobiographical memories [47], stories of life transitions [48] and narratives of major life goals [49]; all such aspects of growth have been linked with higher well-being. Two dimensions, environmental mastery and personal growth, were used to identify three paths of adult development in women, defined as conservers, seekers and achievers [50]. Developmental changes in goal orientations from early to late adulthood have been studied, with higher well-being linked to maintenance of goals and loss prevention [51], while interference among goals predicted lower well-being [52].

Psychother Psychosom 2014;83:10-28 DOI: $10.1159 / 000353263$
Psychological Well-Being Revisited:

Advances in Science and Practice 
Whether eudaimonic well-being improves or declines with aging has been a key focus. Initial cross-sectional studies revealed vulnerabilities in existential aspects of well-being, especially purpose in life and personal growth, among older compared to young or midlife adults $[1,23$, 53]. These patterns have been validated with longitudinal evidence from multiple large samples, including national surveys [31]. Age and well-being varies by cultural context, however, as illustrated by Japanese and US comparisons [54]. Later life well-being is known to be influenced by socioeconomic standing as well $[53,55]$.

Related inquiries have examined subjective aging how adults perceive themselves to be changing as they grow older. Younger and middle-aged adults saw themselves as improving over time, whereas older adults anticipated decline in their well-being in the years ahead [56]. Distinctions have been made between how old people feel versus how old they would ideally like to be, with results showing that higher well-being is predicted by feeling younger but not wanting to be younger [57]. A related study found that adults who perceive that they are younger than they actually are tend to have higher wellbeing [58]. Subjective aging has been compared with their actual aging, which allows for assessment of realism or illusion in self-evaluation. This work has shown that at all ages, greater realism and less illusion predict better functioning, including higher well-being [59].

How individuals negotiate the transitions of adult life has been linked with well-being. One common transition for older adults is relocation, typically involving a move from one's long-standing home to an apartment or retirement community. Older women going through relocation were found to have higher well-being if they engaged in adaptive interpretative processes such as comparing themselves favorably to others in the new setting and showing flexible self-concepts [60-62]. Those with higher environmental mastery, autonomy and personal growth before the move also showed better emotional reactions after the move, particularly if the transition was difficult [63]. Chronic challenges, such as caring for an adult child with mental retardation, have been studied. Analyses from 2 longitudinal studies, 1 focusing on caregiving and the other on relocation, found more positive cross-time changes in well-being among the women who were relocating compared to those providing care to an adult child [64]. However, coping strategies more strongly predicted the well-being of caregiving mothers, thus underscoring possible gains in expertise that accompany challenges of lengthy duration. Other work has also linked the well-being of older adults in residential care facilities, particu- larly positive relations with others and self-acceptance, to coping strategies (active, passive, meaning-based) [65].

In sum, progressing through the developmental tasks of adult life has been linked with higher well-being, although aging itself has been accompanied by declines in purpose in life and personal growth. Those who feel younger than they are, but do not wish to be younger, report higher well-being, although realism rather than illusion in self-evaluation predicts higher well-being. Wellbeing changes as individuals negotiate the events of challenges of adult life, with improvements tied to various psychological processes (social comparisons, flexible selfperceptions, coping strategies).

\section{Personality Correlates}

Psychologists have given considerable attention to how well-being relates to other 'individual difference' variables such as personality traits [66]. An early investigation used the big five model of traits and found that openness to experience was linked with personal growth, agreeableness was linked with positive relations with others, and extraversion, conscientiousness and neuroticism were all linked with environmental mastery, purpose in life and self-acceptance [32]. Many similar patterns were evident in an Iranian sample [67]. Comparative data from US and German samples showed that personality traits rather than self-regulatory characteristics were strong predictors of well-being in both countries [68].

Longitudinal inquiries have addressed links between early personality profiles (age 16) and midlife well-being, finding that teenage females who were more outgoing (extraverted) had higher well-being (all dimensions) in midlife [69]. Teenage neuroticism, in contrast, predicted lower well-being on all dimensions, with the effects mediated through emotional adjustment. Interactions among traits were used to predict changes in well-being over the course of community relocation [70]. Openness to experience, for example, was found to amplify extraversion in predicting higher well-being, but it also amplified neuroticism in predicting greater distress.

A variety of other psychological variables have been linked with well-being. Optimism, for example, predicts higher well-being, with the effects mediated by sense of control [71]. Stable self-esteem predicts higher scores on autonomy, environmental mastery and purpose in life than unstable self-esteem [72]. Emotion regulation strategies predict well-being: reappraisal is a positive predictor, whereas suppression is a negative predictor [73]. Life long-
Ryff 
ings, defined as intense desire for alternative states and life realizations, predict lower well-being [74], but not if life longings are perceived as controllable. Life management strategies (selection, optimization, compensation) have been positively linked with well-being (after controlling for personality and motivational constructs) [75]. The satisfaction of psychological needs contributes to higher wellbeing [76]. Intentional activity changes predict gains in psychological well-being [77], while those who revealed shifts from extrinsic to intrinsic values over the college career had greater increases in psychological well-being [78].

Interpersonal well-being (positive relations with others) has been linked with self-reported empathy [79] as well as emotional intelligence [80], after controlling for personality traits and verbal intelligence. Cross-cultural research has shown that high independence (personal control) predicted higher well-being in the US, whereas high interdependence (relational harmony, measured as the absence of relational strain) predicted higher well-being in Japan [81].

In sum, researchers have studied how personality traits, often construed as heritable characteristics, predict reported levels of well-being using both cross-sectional and longitudinal designs. Numerous other individual difference variables such as optimism, life management strategies, intentional activities, empathy, emotional intelligence, and independence and interdependence have been investigated as factors accounting for reported differences in well-being.

\section{Family Experiences}

Scientists from subfields of sociology as well as family studies have linked diverse family roles, family transitions and unanticipated (nonnormative) family events to psychological well-being. Many adults occupy multiple family roles (parent, child, sibling, spouse). How these statuses are linked with diverse aspects of well-being has been examined in national US surveys [82]. Findings are complex, depending on the age and gender of the respondents, but they highlight that parenting children is more challenging to the well-being of women than men, that the well-being benefits of marriage are fairly similar for men and women, and that having unhealthy aging parents undermines the well-being of young and midlife women. Whether having multiple roles enhances or undermines well-being has been examined [83], with findings supporting the idea that greater role involvement enhances wellbeing. Well-educated women in multiple roles showed

Psychological Well-Being Revisited:

Advances in Science and Practice higher levels of autonomy, with perceived control moderating some links between multiple roles and well-being.

Other studies have investigated what people do in their adult roles. Helping those in one's family has been linked with higher levels of purpose, self-acceptance and positive relations in men, whereas general helping of others was linked with higher purpose and self-acceptance in women [84]. In dealing with the functional decline that accompanies aging, the sense of obligation that people feel to help others protected against declining levels of personal growth and self-acceptance [85]. Family connections and family rituals have been linked to well-being, both in adolescence and midlife [86, 87].

Marital status, per se, has been of considerable interest. The consistently married compared to the divorced, widowed or never married had higher purpose in life, with such differences partly explained by socioeconomic resources [88]. Similarly, being divorced and never married was negatively associated with total well-being (all 6 scales combined), although widowed and never married women reported significantly higher total well-being than men in the same marital groups [89]. In contrast, single women fared better than married women in reported levels of autonomy and personal growth [90]. The transition to divorce or widowhood has been associated with well-being decline, particularly for women [90], although postdivorce well-being was influenced by finding meaning in one's activities [91]. Underscoring well-being as a protective resource, individuals with higher environmental mastery, self-esteem and optimism were better able to adapt to conjugal loss [92].

The parental experience has been extensively linked to adult well-being. Parents reporting positive experiences with their adult children had higher well-being, with such effects linked to midlife generativity [93]; another investigation found differences between parents and childless adults [94]. Childless middle-aged women had higher well-being if they felt they had control over this life longing [95]. How adults themselves were parented also seems to matter - adults who recalled having authoritative rather than authoritarian or uninvolved parents reported greater psychological well-being in midlife, especially men [96]. Those who perceived their parents to be permissive showed lower well-being [97]. How children were doing in life was also linked with parents' well-being. Those whose children had more problems reported compromised well-being [98]. Alternatively, parents who perceived that their children were well adjusted reported higher well-being [33], although children's attainment (e.g. educational standing) was less strongly linked with

Psychother Psychosom 2014;83:10-28 15 
their parental well-being. Interestingly, parents who viewed their children as better adjusted than themselves had lower well-being. The success of sons was more strongly predictive of parents' well-being than the success of daughters [99], although personal comparisons with daughters more strongly predicted parents' well-being than comparisons with sons.

Nonnormative (unplanned, unexpected) family events have been studied. The trauma of losing a child has been shown to have lasting consequences: nearly 20 years after the death, bereaved parents reported poorer well-being, more depressive symptoms and more health problems than comparison parents [100]. However, the same investigation showed that recovery from grief was linked with deepened purpose in life. Other research showed that the death of a child had more detrimental effects on the wellbeing of fathers than mothers [101], while, conversely, having an adult child return to the parental home decreased the well-being of mothers but not fathers. Providing care to an aging parent has been linked with change in depressive symptoms [102], but such effects were reduced among daughters with higher levels of environmental mastery. Being the sibling of an adult with mental illness has been linked with less well-being and more distress compared to adults with normal siblings [103].

Multiple investigations have examined how early family experiences influence adult well-being. Losing a parent to death or divorce prior to age 17 was linked with lower self-acceptance, lower environmental mastery and lower positive relations with others in midlife men [104], whereas parental death in childhood predicted higher autonomy in adult men but greater depression in adult women. Lack of parental support during childhood was linked with increased depressive symptoms and chronic conditions in adulthood [105], with some effects mediated by well-being and self-esteem. Family dynamics (connection and individuation in the family system) during adolescence predicted adult well-being in midlife [106], while discrepancies between adolescents' versus parents' perceptions of family functioning were linked with lower well-being in adolescence. The well-being of elderly parents was linked to positive relationships with their adult children, with such effects traceable to family systems dynamics when children were adolescents [107]. Those who reported experiencing psychological and/or physical violence from parents in childhood had less psychological well-being and more negative affect in adulthood [108].

To summarize, greater role involvement appears to promote higher well-being, although actual activities in family roles matters - helping others seems to enhance purpose and self-acceptance. Those who are consistently married have a well-being advantage compared to the divorced, widowed or never married, but single women score higher on autonomy and personal growth compared to married women. Parenting seems to enhance adult well-being, particularly if one's children are doing well. Loss of a child in adulthood predicts impaired wellbeing decades later, while loss of a parent in childhood predicts lower levels of multiple dimensions of adult wellbeing. Experiencing psychological or physical violence from parents in childhood compromises adult well-being, as does caring for an aging parent, although less so for daughters with high environmental mastery. Overall, family life shows extensive connections to reports of diverse aspects of eudaimonic well-being in adulthood.

\section{Work and Other Life Engagements}

People's workloads have been studied as factors contributing to depression and physical symptoms, but limited research has examined how work influences positive aspects of human functioning. Links between work and psychological well-being were found to differ depending on whether work is paid or unpaid [109]. For women, unpaid work was associated with lower levels of self-acceptance and environmental mastery, whereas for men, paid work was associated with increased levels of personal growth. Well-being has been investigated as an influence on vocational identity and career pursuits. Purpose in life and personal growth were found to contribute to career commitments [110]. Women who saw themselves as falling short of their early career goals had lower levels of purpose in life and higher depressive symptoms, after adjusting for multiple background and health characteristics [111]. A longitudinal cohort of Swedish women found different psychological outcomes for diverse combinations of education, work and family [112]; a key finding showed that women in higher socioeconomic strata exhibited better health and well-being than those in lower strata. Focusing on types of work, women teachers were found to have higher well-being compared to women working in banks who, in turn, had higher well-being than women working in industry [113]. Work and educational experiences were the strongest predictors of wellbeing among older adults, whereas reports of family and relational experience were strongest predictors of wellbeing in midlife [114].

The interface between work and family has been extensively studied. Work-family conflict, particularly as it
16

Psychother Psychosom 2014;83:10-28 DOI: $10.1159 / 000353263$
Ryff 
relates to the demands of caregiving, has been linked with poorer well-being [115]. Alternatively, positive spillover from work to family and from family to work is associated with better well-being outcomes [116]. Changing expectations about how to fulfill work and family roles has been linked with cohort differences in how such roles are tied to well-being $[117,118]$. For example, older women and younger men who adjusted their work schedules to meet family demands had higher self-acceptance, whereas older men and midlife or younger women had lower self-acceptance if they cut back on paid employment to accommodate family demands. Invoking comparisons between Korean and US adults, positive work to family spillover was associated with better adult well-being, but not for Korean women. Alternatively, negative work to family spillover was linked with poorer well-being, especially among US women [119], while family to work spillover was also linked with poorer mental health, particularly among Korean men.

Beyond work and family life, reports of well-being have been linked to participation in volunteer work. Longitudinal data showed that volunteer work over time enhanced eudaimonic but not hedonic well-being [120] and that people with higher well-being at baseline were more likely to volunteer. A similar study [121] used longitudinal data to show that a moderate amount of volunteering (up to $10 \mathrm{~h}$ monthly) and donating to charity was linked with increases in well-being over a 9-year period. Formal volunteering was shown to be protective in dealing with later life role loss [122] - specifically, volunteering moderated the negative effect of role loss on older adults' purpose in life.

Religious participation and religious experience has been linked to well-being. In late adulthood, religiousness was positively associated with interpersonal well-being, whereas spirituality was positively linked with personal growth [123]. Religious involvement predicted higher levels of multiple dimensions of well-being among elderly African Americans [124]. Formal religious participation was associated with higher purpose in life and personal growth but lower autonomy, whereas higher spirituality was associated with higher levels of all aspects of eudaimonic well-being [125].

In sum, well-being appears to contribute to, and be influenced by, career pursuits, with findings varying depending on the types of work pursued. How work and family life come together has been extensively linked to well-being, with evidence showing that conflict between the two realms undermines well-being, while positive spillover from one to the other predicts better well-being. Social change is unfolding in how younger cohorts of men

Psychological Well-Being Revisited:

Advances in Science and Practice and women manage work/family roles, with related differences for reported well-being. Cultural differences of how work and family influence well-being are also evident. Volunteering, especially in later life, is linked with higher well-being, while religious participation has been tied to higher levels of purpose and growth but lower levels of autonomy.

\section{Health and Biological Research}

Arguably, the most novel advances in the science of eudaimonia have occurred in building bridges to physical health, including underlying biological regulation. Such work signals important strides for research on human well-being by showing its relevance for multiple aspects of physical functioning, as well as for health research by demonstrating the importance of attending to people's phenomenological outlooks about how they are dealing with the existential challenges of life. As illustrated below, numerous topics have connected eudaimonia and health.

Regarding self-reported health, the prior section on aging showed that later life physical health predicts psychological well-being via social comparison processes $[126,127]$. Longitudinal analyses further demonstrated that women in the poorest health at baseline who engaged in positive social comparisons showed more positive relations with others and less depression and anxiety at follow-up [128]. In addition, later life stress has been shown to affect health via beliefs about self-efficacy and environmental mastery [129]. On the positive side, mentally healthy adults (those with high levels of multiple aspects of well-being and limited psychological distress) at all ages had fewer chronic conditions compared to adults lacking well-being [130]; they also showed greater productivity and lower health care use [131].

Frailty in old age has been associated with diminished well-being which, in turn, was linked with 5-year mortality, independent of numerous factors [132]. Among frail older adults, however, spirituality emerged as a resource for maintaining psychological well-being [133]. How older adults manage daily life (e.g. environmental mastery) in the face of sensory loss (visual, hearing) has been linked to cognitive resources [134]. Hearing disability has been shown to compromise well-being among older adults [135], with those experiencing late-onset deafness showing significantly lower well-being [136]. How older adults manage end-of-life medical decision making has been linked to their personal and affiliative beliefs rather than to a lack of autonomy [137]. 
Women with fibromyalgia reported lower overall wellbeing than women with rheumatoid arthritis or healthy controls, although those with greater well-being showed less disability and fatigue [138]. Well-being also mediated the relationship between social network size and disability. In patients with rheumatoid arthritis, low environmental mastery has emerged as a useful screen for identifying those vulnerable to developing depression [139]. Research on patients with Parkinson's disease showed compromised levels of sense of coherence and well-being compared to a control group [140]. Psychological factors, including wellbeing, have been linked to adjustment in patients suffering from hypertension [141] as well as congestive heart failure [142], thereby underscoring the importance of well-being in understanding the course of illness.

Psychosocial impairment has been studied in the context of pituitary disease. Such work employed a brief instrument (Psychosocial Index) designed for use in clinical practice [143]. A subset of well-being items were included, along with reduced assessments from other established measures. Findings revealed that patients with endocrine disease, whether pituitary or not, reported more psychological distress and less well-being than controls [144]. A further study used the Psychosocial Index to document that patients with primary aldosteronism had higher levels of psychological distress and lower levels of well-being than controls [145].

Family members and friends of adults with aphasia were found to be reliable informants of their partner's well-being and daily activities but not of their health-related quality of life [146]. Visually impaired young adults participating in a game designed for them (torball) showed significantly higher levels of well-being on 5 of 6 scales compared to nonplayers [147]. Multiple factors (sociodemographic characteristics, psychosocial adaptation to pregnancy, well-being) were investigated as influences on preterm uterine contractions [148]. Women at risk for preterm labor were shown to have lower environmental mastery, lower positive relations with others (especially husband) and lower acceptance of pregnancy compared to gestationally and parity-matched controls. Well-being, along with other demographic, behavioral and medical variables, predicts those likely to use hormone therapy [149].

Several studies have investigated well-being among cancer survivors. Perceived social support and approachoriented coping strategies predict higher eudaimonic well-being among women diagnosed with stage I or II breast cancer [150]. Personal narratives among breast cancer survivors were used to identify those in the positive self-transformation group (compared to the minimal transformation or feeling stuck subgroups) [151]. Such individuals showed higher self-esteem and well-being than the other two groups. Breast cancer survivors, compared to matched controls, showed greater posttraumatic growth, particularly in relating to others and appreciating life [152]. Benefit finding among patients with thyroid cancer, after controlling for demographics and cancer stress, was associated with greater positive affect, wisdom and spiritual well-being but not greater purpose in life or self-acceptance [153]. A national longitudinal study found impairment in mental health, mood and some aspects of well-being in cancer survivors compared to a sociodemographically matched noncancer comparison group, although some areas of vulnerability were evident prior to cancer diagnosis [154]. However, cancer survivors in the same study exhibited resilience in social well-being, spirituality and personal growth. Although personal growth tends to decline with age, cancer status was found to slow the decline in personal growth among younger adults, while it accelerated the decline among older cohorts [155].

Health behaviors have been linked to well-being. Those who engage in diverse types of exercise show higher psychological well-being and self-esteem compared to nonexercising respondents [156], with additional analyses showing that regular physical activity predicts higher levels on all aspects of psychological well-being compared to nonexercisers [157]. An ecological model of exercise in adulthood showed that levels of exercise were linked with educational status, age and race as well as with functional health problems and perceptions of living in a less safe neighborhood [158]. In addition, good mental health, defined with multiple composites including well-being, was greatest among those who exercised, did not smoke, attended church regularly and had frequent contact with friends [159].

A further behavior of interest has been sleep. After adjusting for demographic characteristics and mental and physical health conditions, insomnia significantly predicted both hedonic and eudaimonic well-being, although insomnia symptoms were more strongly related to compromised enjoyment of life than to lowered meaning in life [160]. A further study showed that after adjusting for numerous factors, optimal sleepers reported higher levels of environmental mastery, personal growth, positive relations with others, purpose in life and self-acceptance as well as reduced symptoms of depression and anxiety, thus underscoring sleep as a resource related to stress management and self-regulation [161]. Longitudinal findings over a 10 -year period showed that recurrent insomnia is
18

Psychother Psychosom 2014;83:10-28 DOI: $10.1159 / 000353263$
Ryff 
particularly detrimental to well-being [162]. A separate longitudinal sample of aging women showed that sleep declined over time, but not for all respondents [163]; those with higher well-being (all dimensions except autonomy) and lower depression at baseline showed reduced odds of being in the sleep-disrupted group over time.

Weight and body consciousness have been linked with well-being. Those who are overweight or obese showed lower well-being compared to normal weight groups, particularly among women [164]. In addition, obese respondents (body mass index of 35 or higher) were more likely to report employment discrimination and interpersonal mistreatment and lower levels of self-acceptance, with the latter effect mediated by the perception that they had been discriminated against on the basis of appearance. A sample of college students and their middle-aged mothers showed that body consciousness (e.g. feeling one does not meet cultural standards) was linked to lower well-being in both groups, with body esteem tied more strongly to the well-being of daughters than mothers [165]. Alternatively, overweight women showed that those who endorsed the need for social change in attitudes toward overweight people had higher body self-esteem and self-acceptance and lower body shame than those who endorsed only personal acceptance of body size [166]. Age-related changes and cohort differences in models of body experience were studied in a 10-year longitudinal investigation [167], with results showing that young women's body surveillance and body shame decreased over time, while body esteem increased.

Innovative research has linked eudaimonic well-being to biological measures to investigate whether subjective indicators of meaning, purpose and growth are accompanied by better regulation of physiological systems. Initial work, based on a sample of older women [168], showed that those with higher levels of eudaimonic well-being had lower levels of daily salivary cortisol, lower proinflammatory cytokines, lower cardiovascular risk and longer-duration REM sleep compared to those with lower well-being [168]. Hedonic well-being, in contrast, showed minimal linkage to the biomarker assessments. The same aging sample showed that, after adjusting for covariates, women with higher scores on positive relations with others had lower levels of plasma IL-6, whereas those reporting higher scores on purpose in life had lower levels of the soluble IL-6 receptor (sIL-6R) [169]. Another study showed lower cortisol output among individuals with high psychological well-being [170]. Lower cortisol levels were found among individuals showing self-enhancing cognitions, with such effects mediated by psychological

Psychological Well-Being Revisited:

Advances in Science and Practice resources, including well-being [171]. Links between well-being and immune function were investigated via cytokine responses to influenza or hepatitis A immunization; significant positive correlations were found between well-being and production of IFN- $\gamma$ and IL-10 [172].

The interplay between positive relationships with others, sleep quality and plasma IL-6 has been investigated [173], with findings showing that higher levels of this marker, implicated in cardiovascular and rheumatological disease as well as osteoporosis and Alzheimer's disease, were evident among women with poor sleep efficiency and poor social relationships. There was also evidence of compensatory effects: women with poor sleep efficiency but good relationships, as well as women with poor relationships but good sleep, had levels of IL-6 comparable to those with the protective influence of both factors. Extending the inquiry to a national sample, social engagement was found to moderate the association of sleep complaints on both IL- 6 and the soluble adhesion molecule E-selectin in men but not in women [174]; similarly, social engagement moderated the link between actigraphy-measured sleep efficiency and IL-6, but again only for men.

Psychological well-being is increasingly investigated as a moderator of links between inequality and biological risk factors. Adults with lower educational attainment were found to have higher levels of IL-6, after adjusting for numerous factors [34], but educational status interacted with psychological well-being in predicting levels of IL-6: among those with a high-school education or less, higher eudaimonic well-being (multiple dimensions) and higher positive affect were associated with lower levels of IL-6. The results thus revealed protective effects of wellbeing in the face of educational disadvantage. Socioeconomic status and well-being were used to predict crosstime changes in glycosylated hemoglobin (HbAlc), a marker of glycemic control, among nondiabetic older women [175]. Higher income predicted lower cross-time profiles of HbAlc, but measures of well-being (purpose in life, personal growth, positive affect) moderated the relationship between income and HbAlc. Shifting to challenges of aging, psychological well-being has been found to moderate relationships between later life comorbidity and inflammation [176]. That is, many older adults live with multiple chronic conditions known to fuel further inflammatory processes that can contribute to subsequent functional decline. Although IL-6 and CRP levels were shown to be higher among those with increased numbers of chronic conditions, such effects were buffered by respondents' levels of well-being: older adults with higher levels of purpose in life and positive relation- 
ships with others had levels of inflammation comparable to those with fewer chronic conditions.

Most recently, gene expression profiles related to inflammation have been examined with findings showing highly divergent transcriptome profiles for hedonic versus eudaimonic well-being [224]. Specifically, high hedonic well-being was associated with upregulated expression of proinflammatory genes and decreased expression of genes involved in antibody synthesis, a pattern known as CTRA (stress-related conserved transcriptional response to adversity). Those high in eudaimonic well-being, in contrast, showed CTRA downregulation (i.e., decreased expression of proinflammatory genes and increased expression of antibody synthesis genes). These patterns were independent of demographic, health, and behavioral risk factors. Eudaimonia thus appeared to show health-related benefits for gene expression that were not apparent for hedonia.

Shifting to integrative measures of biological risk, individuals with higher levels of both eudaimonic and hedonic well-being were at reduced risk of metabolic syndrome, after adjusting for confounds [177], with such effects robust across demographic subgroups (age, gender, educational status, race). A study of personality change over 10 years found that those who became less conscientious and more neurotic over time had both lower well-being and worse metabolic profiles [178]. Another study examined multiple topics in a healthy population (sources or distress, psychiatric and psychosomatic symptoms, well-being, social and occupational functioning) and found that those meeting multiple criteria of distress had lower levels of serum proteins, erythrocytes and immune differential count compared to their nondistressed counterparts [179].

Particular interest has been shown in purpose in life, a key existential dimension of eudaimonic well-being, and its links to disease outcomes as well as mortality. A longitudinal epidemiological study of aging showed that those with higher levels of purpose in life at baseline were at reduced risk for incident Alzheimer's disease and mild cognitive impairment compared to those with lower purpose in life, after adjusting for confounds [180]. High purpose in life also predicted reduced rates of mortality 7 years later [181]. In the same study, postmortem examination of organic pathology in the brain showed that links between multiple indicators of pathology and cognitive impairment differed depending on levels of purpose in life [182]. Specifically, respondents with higher purpose in life exhibited better cognitive function, despite the increased burden of disease. Such effects persisted after controlling for numerous confounds. Other recent work, based on a large national longitudinal study of aging, has shown that purpose in life is linked with reduced risk of stroke [183] and reduced risk of myocardial infarction among those with coronary heart disease [184], after adjusting for numerous covariates.

The neural correlates of well-being are receiving increased attention. Using electrophysiological indicators, an initial study showed that adults reporting higher levels of eudaimonic and hedonic well-being showed greater left than right superior frontal activation in response to emotional stimuli [185]; furthermore, the eudaimonic effects were maintained after adjusting for the hedonic indicators, but the reverse was not true (brain-based links to hedonic well-being were no longer significant after controlling for eudaimonic well-being). Another study used functional magnetic resonance imaging to investigate differences in amygdala activation in response to negative relative to neutral stimuli [186]. Findings showed that those who were faster to evaluate negative information showed increased left and right amygdala activation, but these effects varied depending on overall profiles of psychological wellbeing. Individuals with high well-being were slower to evaluate such information and showed reduced amygdala activation and increased ventral anterior cingulated cortex activation. Another recent study has documented that those showing sustained activity in the ventral striatum and dorsolateral prefrontal cortex while viewing positive stimuli reported higher eudaimonic well-being as well as lower cortisol output [187]. These results suggest that sustained engagement of reward circuitry when encountering positive events may underlie the phenomenology of wellbeing as well as related regulation of the hypothalamic pituitary adrenal axis. Finally, eudaimonic well-being has been linked with insular cortex volume, which is involved with a variety of higher-order functions. Results showed positive links between personal growth, positive relations and purpose in life and right insular cortex grey matter volume [188]. The positive relations scale was also significantly associated with left insula volume.

To summarize, growing evidence indicates that wellbeing is compromised in those with diverse physical illnesses and disabilities, although its presence has been implicated in the course of illness, with some individuals showing gains or maintenance of well-being in the aftermath of disease. Importantly, epidemiological studies document the protective influence of purpose in life vis-à-vis risk of cognitive impairment and Alzheimer's disease, even in the presence of organic pathology in the brain. Purpose in life is also linked with reduced risk of stroke and myocardial infarction. Other inquiries have linked as-
Ryff 
pects of eudaimonic well-being to health behaviors (exercise, sleep, weight). Numerous studies show higher wellbeing predicts better biological regulation, measured in terms of stress hormones (such as cortisol) as well as inflammatory markers and cardiovascular risk factors. These benefits were evident in the context of risk such as socioeconomic disadvantage and increased chronic conditions in later life. Gene expression has been found to vary depending on type of well-being: eudaimonia was linked with downregulation of proinflammatory genes and increased expression of antibody synthesis genes, whereas hedonic well-being was linked with the reverse pattern (upregulation of proinflammatory genes and decreased expression of antiobody synthesis genes). The neuroscience of eudaimonia is emerging, with initial evidence showing that those with higher well-being have differential brain responses to negative stimuli (less amygdala activation, more engagement of higher-order cortical structures) and positive stimuli (sustained activation of reward circuitry), with the latter effect accompanied by reduced cortisol output. Those with higher well-being also show greater insular cortex volume. Eudaimonia is thus increasingly implicated in health and biological regulation as well as in brain-based processes, with an overarching message that it appears to serve adaptive, protective functions.

\section{Clinical and Intervention Studies}

How well-being intersects with mental illness has received considerable attention. A national sample of US adults found that risk of a major depressive episode was substantially higher among individuals who lacked multiple aspects of well-being [189]. Measurement work further clarified that emotional, psychological and social well-being constitute separate unipolar dimensions relative to measures of major depressive episodes, generalized anxiety, panic disorder and alcohol dependence [190]. When combined, only a small proportion of the population (16.6\%) showed complete mental health (presence of the positive, absence of the negative), although such individuals had fewest limitations in activities of daily living and fewest missed days at work compared to other mental health categories. Longitudinal data showed that crosstime gains in mental health (defined in terms of well-being) predicted cross-time declines in mental illness, thus underscoring the need for greater public health attention on the promotion of positive mental health [191].

Other investigators have probed linkages between specific mental disorders and well-being; 1 study examined

Psychological Well-Being Revisited:

Advances in Science and Practice how well-being moderates insight in patients with schizophrenia or psychotic disorders who had paranoid symptoms [192]. The paranoid group with low insight showed higher self-acceptance, autonomy and personal growth compared to the paranoid group with high insight. Additional work examined implicit and explicit self-esteem (assessed in part with the self-acceptance scale) in patients with persecutory delusions [193]. Depressed patients showed lower explicit self-esteem than did paranoid and healthy control participants, but those with persecutory delusions had significantly lower implicit self-esteem than healthy controls. The findings were interpreted with a focus on defense mechanisms in the paranoid group.

Individuals in the chronic phase of schizophrenia reported significantly lower levels in all 6 dimensions of well-being relative to controls. Further, negative symptoms and depression predicted these aspects of well-being in the schizophrenic sample [194]. Among residents in aged care settings, psychological well-being (environmental mastery, purpose in life, autonomy) was found to be more important in understanding depression than traditional risk factors such as medical illness or disability [195]. Posttraumatic stress disorder in Pakistani earthquake survivors was linked with protective psychosocial factors [196], with findings showing that among those who met posttraumatic stress disorder criteria, symptoms were lower if they had higher levels of purpose in life.

Psychiatric paradigms often define recovery as reduction in symptoms or the absence of psychological distress. Moving beyond this formulation, studies in remitted patients with mood and anxiety disorders [197], as well as panic disorder and agoraphobia [198], revealed significantly lower levels on multiple aspects of psychological well-being. Such findings clarify that complete recovery involves more than reduction of distress; it must also include improvements in well-being which, in turn, underscore the need for sequential therapeutic strategies.

A prominent example is 'well-being therapy' developed by Fava [199] and Fava et al. [200], which make explicit use of the eudaimonic approach to psychological well-being. Conceived as an addition to cognitive behavioral therapy in treating the residual phase of major depression, the goal is to promote patients' experiences of the positive as a way of preventing relapse. The intervention requires keeping daily diaries of positive experiences, which then become the focus in therapy wherein patients learn how to prevent premature curtailment of positive experiences as well as how to enrich and extend them. For example, if a diary entry pertains to a good social interaction experience, the clinician expands on the meaning of 
positive relationships with others to broaden the patient's thinking about what good interpersonal relations might entail. Initial findings with such treatment revealed significant improvements after discontinuation of drug therapy compared to no significant change in the clinical management group. A follow-up study showed that benefits in the prevention of relapse of major depression persisted over a 6-year period [201]. Subsequent work extended the approach to treating generalized anxiety disorder [202, 203], thereby underscoring the benefits of sequential treatment strategies (i.e. cognitive behavioral therapy followed by well-being therapy) in achieving sustained recovery. The combination of cognitive behavioral treatment with well-being therapy was also employed in a randomized clinical trial to treat cyclothymic disorder [204, 205]. Findings on all outcomes showed greater improvement in the cognitive behavioral therapy/well-being therapy group compared to the clinical management group. Taken together, these initiatives speak to the usefulness of well-being therapy in preventing relapse of mood, anxiety and cyclothymic disorders as well as treating patients who fail to respond to standard pharmacological or psychotherapeutic treatments or have body image disturbances [206]. Throughout, these approaches have underscored the need for a more expansive concept of recovery - no longer is reduction in number and severity of symptoms sufficient; new criteria call for patients to experience wellbeing that is known to reduce future risk for relapse [207].

Other types of psychiatric interventions have utilized assessments of well-being to evaluate the efficacy of treatment. For example, reports of psychological well-being were used to document the effectiveness of a cognitive behavioral therapy, known as Graduated Recovery Intervention Program, designed for those experiencing an episode of psychosis [208]. Gains in 4 of 6 dimensions of well-being were used to demonstrate the efficacy of strategies to treat depression among individuals suffering from multiple sclerosis [209]. A community-based intervention program for people with aphasia and their families showed gains over a 6-month period in 5 of 6 dimensions of wellbeing among clients and family members [210]. Patients with rheumatoid arthritis participating in a mindfulnessbased stress reduction program showed significant improvement in psychological well-being after an 8-week course and a 4-month maintenance program [211]. A loving-kindness meditation conducted with patients with schizophrenia spectrum disorders produced gains in wellbeing and reductions in negative symptoms [212].

Interventions have been conducted with nonclinical samples as well, thus revealing shifts toward prevention of mental or physical health disorders. For example, Ruini et al. [213] adapted well-being therapy to school settings in an effort to prevent psychological disorders such as depression during adolescence. A comparison of students receiving the intervention with an attention-placebo group revealed significant improvements in personal growth along with reductions in multiple indicators of distress [214]. A mental health program designed to promote adult resilience in the workplace used interpersonal and cognitive behavioral therapy over an 11-week intervention; findings showed significant improvements in mental health and well-being [215]. Similar effects were obtained with a second, shorter (7-week) intervention [216]. The emotional disclosure of trauma has been shown to improve sense of mastery, personal growth and selfacceptance, while decreasing depressive symptoms, anxiety and somatization [217]. Gains in all aspects of wellbeing resulted from a retrospective life review program conducted with community-dwelling older women [218].

Finally, meditation interventions have utilized assessments of well-being; 1 study involved a 3-month intensive meditation program designed to improve self-regulation strategies [219]. Findings revealed improvement in response inhibition in the treatment compared to the control group as well as accompanying gains in adaptive functions, including a composite of measure of well-being. Effects were sustained 5 months posttraining. Another study examined the effect of a 3-month meditation retreat on telomerase activity as well as mindfulness and purpose in life [220]. Compared to the wait-list control group, those receiving intensive meditation training showed significantly greater telomerase activity and increases in both psychological outcomes, with the latter effects mediated by increases in perceived control and decreases in neuroticism.

To recapitulate, it is now well established that eudaimonic well-being is not simply the flipside of psychological distress. Both are important indicators of overall mental health, and population studies reveal diverse combinations of how the two domains come together. Increasingly, well-being is considered in research on specific mental disorders (schizophrenia, depression, panic disorder, cyclothymia, agoraphobia, post-traumatic stress disorder) that have been shown to compromise the individual's sense of mastery, growth, purpose and positive self-regard. It is also the case that the presence of wellbeing is sometimes accompanied by reduced symptoms of these disorders. The greatest advances have occurred in clinical intervention studies where improvements in well-being now constitute innovative new treatment targets needed to prevent relapse. Multiple studies docu- 
ment long-term treatment benefits associated with wellbeing therapy. Other psychiatric interventions have employed measures of well-being to validate the effectiveness of diverse treatment programs. Interventions have been extrapolated beyond the clinic to school and workplace settings with the goal of enhancing well-being so as to prevent mental illness and promote resilience. Meditation-training programs have been shown to increase eudaimonic aspects of psychological well-being.

\section{Summary Observations and Future Directions}

As illustrated above, the eudaimonic approach to psychological well-being has become a flourishing arena of scientific inquiry and clinical practice. Why this has occurred merits reflection. Presumably, it stems from the fact that these phenomenological indicators capture core aspects of what it means to be human: that is, to strive, to be proactive, to make meaning and, as articulated by Aristotle over 2,000 years ago, to pursue the highest good that is within us. These ideals about human functioning, along with refinements from existential, humanistic, developmental and clinical psychology, paved the way for new empirical targets in scientific research [1]. Measures designed to operationalize eudaimonic well-being have now been incorporated into many fields as tools to evaluate people's negotiations through the challenges and transitions of adulthood and aging as well as their management of work, family and community life. Psychological wellbeing, it seems, is becoming as foundational to defining who we are as were personality traits some decades ago.

Without question, the most informative advances have come from linking psychological well-being to physical health, biological regulation and neuroscience. These scientific strides need to be broadened and deepened, but growing evidence shows that qualities such as purposeful engagement, self-realization and growth, and enlightened self-regard are relevant empirical influences on how long and how well people live. Epidemiological studies document that purpose in life predicts reduced risk for numerous diseases (Alzheimer's disease, stroke, myocardial infarction), and a proliferation of studies have begun to probe underlying biological mechanisms measured in terms of neuroendocrine regulation, inflammatory processes, including gene expression, glycemic control and cardiovascular risk. Multiple studies have linked phenomenological indicators of well-being to reduced amygdala activation in response to negative stimuli, sustained activity in the ventral striatum and dorsolateral prefrontal

Psychological Well-Being Revisited:

Advances in Science and Practice cortex when viewing positive stimuli, and increased insular cortex volume. Of importance in the research that lies ahead is the need to build bridges across these different levels of analysis - phenomenology, biology, genetics and neuroscience, all of which play a part in accounting for adaptive human functioning.

Given the prior lines of inquiry reviewed above, it is both sensible and appropriate that interventions are flourishing to enhance and improve individuals' experiences of well-being as a route to nurturing sustained recovery from diverse mental health problems such as major depression, generalized anxiety disorder, cyclothymic disorder, schizophrenia and posttraumatic stress. These advances have been accompanied by preventive interventions outside the clinic intended, for example, to reduce the risk of depression in adolescence and old age. Clearly, the emphasis on psychological well-being has launched important new directions in research translation, application and education.

The way forward includes rich possibilities. One relevant priority is to nurture greater interplay among the multiple domains summarized in this review. The 6 thematic areas examined each have their own scientific communities, including their own journals. Enlightened multidisciplinary research is needed to work across these domains. That is, psychological studies of adult development and aging, along with personality research, are enriched by attending to the contexts of people's lives (work and family experiences), with well-being serving as a vital thread throughout. These same areas of psychosocial and contextual inquiry, in turn, are critically needed in research on health, biological regulation, genetics and neuroscience, which is often disconnected from the substance of people's lives and, importantly, from their phenomenological outlooks on how things are going.

Weaving these pieces together demands data sets that include indepth measures across multiple domains as well as longitudinal follow-ups; 1 such study is MIDUS (Midlife in the US, www.midus.wisc.edu), the data from which are publicly available. MIDUS is thus a major forum for carrying out biopsychosocial investigations that are open to all interested scientists. Thanks to parallel data collected from a large Japanese study known as MIDJA (Midlife in Japan), the integrative work has also begun to embrace cultural influences on what constitutes the highest goods in life and how they matter for health.

A fruitful future direction, given decades of health research on why people become ill (mentally or physically), diseased, disabled and die, is human resilience - namely, 
the capacity of some to experience and sustain their wellbeing, perhaps even deepen it, despite the challenges that life presents to them, be they loss events, social inequalities, unexpected traumas or living in a sometimes hostile world [221]. MIDUS, because of its notable depth in assessing well-being, along with all of the thematic domains covered above, is uniquely suited for such research. Indeed, MI-
DUS has become the primary hub for studies of human resilience [222]. Much future work remains to be done in probing hypotheses about how eudaimonic well-being affords protection under diverse conditions of challenge and the mechanisms through which such effects occur. Nurturing these integrative pursuits and their implications for the world of practice is a worthy goal for the next 25 years.

\section{References}

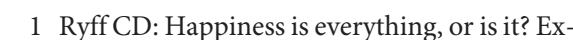
plorations on the meaning of psychological well-being. J Pers Soc Psychol 1989;57:10691081.

$>2$ Ryff CD, Singer BH: Psychological well-being: meaning, measurement, and implications for psychotherapy research. Psychother Psychosom 1996;65:14-23.

3 Campbell A: The Sense of Well-Being in America. New York, McGraw-Hill, 1981.

4 Veroff J, Douvan E, Kulka RA: The Inner American: A Self-Portrait from 1957 to 1976. New York, Basic Books, 1981.

5 Bradburn NM: The Structure of Psychological Well-Being. Chicago, Aldine, 1969.

$\checkmark 6$ Diener E: Subjective well-being. Psychol Bull 1984;95:542-575

7 Allport GW: Pattern and Growth in Personality. New York, Holt, Rinehart, \& Winston, 1961.

8 Bühler C: The curve of life as studied in biog raphies. J Appl Psychol 1935;43:653-673.

9 Erikson EH: Identity and the life cycle: selected papers. Psychol Issues 1959;1:1-171.

10 Frankl VE: The spiritual dimension in existential analysis and logotherapy. J Individ Psychol 1959;15:157-165.

11 Jahoda M: Current Concepts of Positive Mental Health. New York, Basic Books, 1958.

12 Jung CG: Modern Man in Search of a Soul. 27 New York, Harcourt, Brace \& World, 1933.

13 Maslow AH: Toward a Psychology of Being, ed 2. New York, Van Nostrand, 1968

14 Neugarten BL: Personality change in late life: a developmental perspective; in Eisodorfer C, Lawton MP (eds): The Psychology of Adult Development and Aging. Washington, American Psychological Association, 1973, pp 311-335.

15 Wiggins JS: Personality and Prediction: Principles of Personality Assessment. Menlo Park Addison-Wesley, 1980.

$\checkmark 16$ Ryan RM, Deci EL: On happiness and human potentials: a review of research on hedonic and eudaimonic well-being. Annu Rev Psychol 2001;52:141-166.

17 Aristotle: The Nicomachean Ethics. New York, Oxford University Press, 1925.

18 Ryff CD, Singer BH: Best news yet on the sixfactor model of well-being. Soc Sci Res 2006; 35:1103-1119.

19 Cheng S-T, Chang AC: Measuring psychological well-being in the Chinese. Pers Individ Dif 2005;38:1307-1316.
20 Clarke PJ, Marshall VW, Ryff CD, Wheaton $\mathrm{B}$ : Measuring psychological well-being in the Canadian Study of health and aging. Int Psychogeriatr 2001;13:79-90.

21 Gallagher MW, Lopez SJ, Preacher KJ: The hierarchical structure of well-being. J Pers 2009; 77:1025-1050.

22 Lindfors P, Berntsson L, Lundberg U: Factor structure of Ryff's psychological well-being scales in Swedish female and male white-collar workers. Pers Individ Dif 2006;40:12131222.

23 Ryff CD, Keyes CLM: The structure of psychological well-being revisited. J Pers Soc Psychol 1995;69:719-727.

24 Sirigatti S, Stefanile C, Giannetti E, Iani L, Penzo I, Mazzeschi A: Assessment of factor structure of Ryff's Psychological Well-Being Scales in Italian adolescents. Boll Psicolog Appl 2009;259:30-50.

25 Springer KW, Hauser RM: An assessment of the construct validity of Ryff's scales of psychological well-being: method, mode, and measurement effects. Soc Sci Res 2006;35: 1080-1102.

26 van Dierendonck D: The construct validity of Ryff's scales of psychological well-being and its extension with spiritual well-being. Pers Individ Dif 2004;36:629-643.

van Dierendonck D, Díaz D, Rodríguez-Carvajal R, Blanco A, Moreno-Jiménez B: Ryffs six-factor model of psychological well-being, a Spanish exploration. Soc Indic Res 2008;87: 473-479.

28 Abbott R, Ploubidis G, Huppert F, Kuh D, Croudace T: An evaluation of the precision of measurement of Ryff's Psychological WellBeing Scales in a population sample. Soc Indic Res 2010;97:357.

29 Kafka GJ, Kozma A: The construct validity of Ryff's scales of psychological well-being (SPWB) and their relationship to measures of subjective well-being. Soc Indic Res 2002;57: 171-190.

30 Springer KW, Hauser RM, Freese J: Bad news indeed for Ryff's six-factor model of well-being. Soc Sci Res 2006;35:1120-1131.

31 Springer KW, Pudrovska T, Hauser RM: Does psychological well-being change with age? Longitudinal tests of age variations and further exploration of the multidimensionality of Ryff's model of psychological well-being. Soc Sci Res 2011;40:392-398.
32 Schmutte PS, Ryff CD: Personality and wellbeing: reexamining methods and meanings. J Pers Soc Psychol 1997;73:549-559.

-33 Ryff CD, Lee YH, Essex MJ, Schmutte PS: My children and me: midlife evaluations of grown children and of self. Psychol Aging 1994;9: 195-205.

34 Morozink JA, Friedman EM, Coe CL, Ryff $\mathrm{CD}$ : Socioeconomic and psychosocial predictors of interleukin- 6 in the MIDUS national sample. Health Psychol 2010;29:626-635.

35 Fava GA, Rafanelli C, Cazzaro M, Conti S, Grandi S: Well-being therapy: a novel psychotherapeutic approach for residual symptoms of affective disorders. Psychol Med 1998;28: 475-480.

36 Tomba E, Bech P: Clinimetrics and clinical psychometrics: macro- and micro-analysis. Psychother Psychosom 2012;81:333-343.

-37 Tomba E, Belaise C, Ottolini F, Ruini C, Bravi A, Albieri E, Rafanelli C, Caffo E, Fava GA: Differential effects of well-being promoting and anxiety management strategies in a nonclinical school setting. J Anxiety Disord 2010; 24:326-333.

38 Fava GA, Tomba E: Increasing psychological well-being and resilience by psychotherapeutic methods. J Pers 2009;77:1903-1934

39 Vleioras G, Bosma HA: Are identity styles important for psychological well-being? J Adolesc 2005;28:397-409.

40 Cheng S-T: Generativity in later life: perceived respect from younger generations as a determinant of goal disengagement and psychological well-being. J Gerontol B Psychol Sci Soc Sci 2009;64:45-54.

41 Grossbaum MF, Bates GW: Correlates of psychological well-being at midlife: the role of generativity, agency and communion, and narrative themes. Int J Behav Dev 2002;26:120-127.

42 Keyes CLM, Ryff CD: Generativity in adult lives: social structural contours and quality of life consequences; in McAdams DP, de St. Aubin E (eds): Generativity and Adult Development: Psychosocial Perspectives on Caring for and Contributing to the Next Generation. Washington, American Psychological Association, 1998, pp 227-263.

43 James JB, Zarrett N: Ego integrity in the lives of older women: a follow-up of mothers from the Sears, Maccoby, and Levin (1951) Patterns of Child Rearing Study. J Adult Dev 2005;12: 155-167. 
44 James JB, Zarrett N: Ego integrity in the lives of older women. J Adult Dev 2006;13:61-75.

-45 Riggle EDB, Rostosky SS, Danner F: LGB identity and eudaimonic well-being in midlife. J Homosex 2009;56:786-798.

-46 Saunders KJ, Kashubeck-West S: The relations among feminist identity development, gender-role orientation, and psychological well-being in women. Psychol Women Q 2006;30:199-211.

47 Bauer JJ, McAdams CP, Sakaedura AR: Interpreting the good life: growth memories in the lives of mature, happy people. J Pers Soc Psychol 2005;88:203-217.

48 Bauer JJ, McAdams DP: Personal growth in adults' stories of life transitions. J Pers 2004; 75:573-602.

49 Bauer JJ, McAdams DP: Growth goals, maturity, and well-being. Dev Psychol 2004;40: 114-127.

50 Helson R, Srivastava S: Three paths of adult development: conservers, seekers, and achievers. J Pers Soc Psychol 2001;80:995-1010.

51 Ebner NC, Freund AM, Baltes PB: Developmental changes in personal goal orientation from young to late adulthood: from striving for gains to maintenance and prevention of losses. Psychol Aging 2006;21:664-678.

52 Riediger M, Freund AM: Interference and facilitation among personal goals: differential associations with subjective well-being and persistent goal pursuit. Pers Soc Psychol Bull 2004;30:1511-1523.

-53 Clarke PJ, Marshall VW, Ryff CD, Rosenthal CJ: Well-being in Canadian seniors: findings from the Canadian Study of Health and Aging. Can J Aging 2000;19:139-159.

-54 Karasawa M, Curhan K, Markus H, Kitayama S, Love G, Radler B, Ryff C: Cultural perspectives on aging and well-being: a comparison of Japan and the United States. Int J Aging Hum Dev 2011;73:73-98.

55 Keyes CLM, Shmotkin D, Ryff CD: Optimizing well-being: the empirical encounter of two traditions. J Pers Soc Psychol 2002;82:10071022.

56 Ryff CD: Possible selves in adulthood and old age: a tale of shifting horizons. Psychol Aging 1991;6:286-295.

57 Keyes CL, Westerhof GJ: Chronological and subjective age differences in flourishing mental health and major depressive episode. Aging Ment Health 2012;16:67-74.

58 Ward RA: How old am I? Perceived age in middle and later life. Int J Aging Hum Dev 2010;71:167-184

-59 Lachman ME, Röcke C, Rosnick C, Ryff CD: Realism and illusion in Americans' temporal views of their life satisfaction: age differences in reconstructing the past and anticipating the future. Psychol Sci 2008;19:889-897.

60 Kling KC, Ryff CD, Essex MJ: Adaptive changes in the self-concept during a life transition. Pers Soc Psychol Bull 1997;23:981990.
61 Kwan CML, Love GD, Ryff CD, Essex MJ: The role of self-enhancing evaluations in a successful life transition. Psychol Aging 2003;18:3-12.

62 Ryff CD, Essex MJ: The interpretation of life experience and well-being: the sample case of relocation. Psychol Aging 1992;7:507-517.

63 Smider NA, Essex MJ, Ryff CD: Adaptation to community relocation: the interactive influence of psychological resources and contextual factors. Psychol Aging 1996;11:362-372.

64 Kling KC, Seltzer MM, Ryff CD: Distinctive late-life challenges: implications for coping and well-being. Psychol Aging 1997;12:288-295.

65 Schanowitz JY, Nicassio PM: Predictors of positive psychosocial functioning of older adults in residential care facilities. J Behav Med 2006;29:191-201.

66 Ryff CD: Challenges and opportunities at the interface of aging, personality, and well-being; in John OP, Robins RW, Pervin LA (eds): Handbook of Personality: Theory and Research. New York, Guilford Press, 2008, pp 399-418.

67 Joshanloo M, Rastegar P: The big five personality traits and self-esteem as predictors of eudaimonic well-being. J Iran Psychol 2007;4: 13-24.

68 Staudinger UM, Fleeson W, Baltes PB: Predictors of subjective physical health and global well-being: similarities and differences between the United States and Germany. J Pers Soc Psychol 1999;76:305-319.

-69 Abbott RA, Croudace TJ, Ploubidis GB, Kuh D, Richards M, Huppert FA: The relationship between early personality and midlife psychological well-being: evidence from a UK birth cohort study. Soc Psychiatry Psychiatr Epidemiol 2008;43:679-687.

70 Bardi A, Ryff CD: Interactive effects of traits on adjustment to a life transition. J Pers 2007; 75:955-984.

71 Ferguson SJ, Goodwin AD: Optimism and well-being in older adults: the mediating role of social support and perceived control. Int J Aging Hum Dev 2010;71:43-68.

72 Paradise AW, Kernis MH: Self-esteem and psychological well-being: implications of fragile self-esteem. J Soc Clin Psychol 2002;21: 345-361.

73 Gross JJ, John OP: Individual differences in two emotion regulation processes: implications for affect, relationships, and well-being. J Pers Soc Psychol 2003;85:348-362.

74 Scheibe S, Freund AM, Baltes PB: Toward a developmental psychology of Sehnsucht (life longings): the optimal (utopian) life. Dev Psychol 2007;43:778-795.

75 Freund AM, Baltes PB: The adaptiveness of selection, optimization, and compensation as strategies of life management: evidence from a preference study on proverbs. J Gerontol B Psychol Sci Soc Sci 2002;57B:426-434.

76 Milyavskaya M, Philippe FL, Koestner R: Psychological need satisfaction across levels of experience: their organization and contribution to general well-being. J Res Pers 2012;47: $41-51$.
7 Sheldon KM, Lyubomirsky S: Achieving sustainable gains in happiness: change your actions, not your circumstances. J Happiness Stud 2006;7:55-86.

78 Sheldon KM: Positive value change during college: normative trends and individual differences. J Res Pers 2005;39:209-223.

79 Grühn D, Rebucal K, Diehl M, Lumley M, Labouvie-Vief G: Empathy across the adult lifespan: longitudinal and experience-sampling findings. Emotion 2008;8:753-765.

80 Lopes PN, Salovey P, Straus R: Emotional intelligence, personality, and the perceived quality of social relationships. Pers Individ Dif 2003;35:641-658.

-81 Kitayama S, Karasawa M, Curhan KB, Ryff $\mathrm{CD}$, Markus HR: Independence and interdependence predict health and wellbeing: divergent patterns in the United States and Japan. Front Psychol 2010;1:1-10.

82 Marks NF, Bumpass LL, Jun H: Family roles and well-being during the middle life course; in Brim OG, Ryff CD, Kessler RC (eds): How Healthy Are We? A National Study of WellBeing at Midlife. Chicago, University of Chicago Press, 2004, pp 514-549.

83 Ahrens CJC, Ryff CD: Multiple roles and wellbeing: sociodemographic and psychological moderators. Sex Roles 2006;55:801-815.

84 Schwartz CE, Keyl PM, Marcum JP, Bode R: Helping others shows differential benefits on health and well-being for male and female teens. J Happiness Stud 2009;10:431-448.

85 Greenfield EA: Felt obligation to help others as a protective factor against losses in psychological well-being following functional decline in middle and later life. J Gerontol B Psychol Sci Soc Sci 2009;64:723.

86 Crespo C, Kielpikowski M, Pryor J, Jose PE: Family rituals in New Zealand families: links to family cohesion and adolescents' well-being. J Fam Psychol 2011;25:184-193.

87 Bell LG, Bell DC: Effects of family connection and family individuation. Attach Hum Dev 2009;11:471-490.

88 Bierman A, Fazio EM, Milkie MA: A multifaceted approach to the mental health advantage of the married: assessing how explanations vary by outcome measure and unmarried group. J Fam Issues 2006;27: 554-582.

89 Shapiro A, Keyes C: Marital status and social well-being: are the married always better off? Soc Indic Res 2008;88:329-346.

90 Marks NF, Lambert JD: Marital status continuity and change among young and midlife adults: longitudinal effects on psychological well-being. J Fam Issues 1998;19:652-686.

91 Bevvino DL, Sharkin BS: Divorce adjustment as a function of finding meaning and gender differences. J Divorce Remarriage 2003;39: 81-97.

92 Montpetit MA, Bergeman CS, Bisconti TL, Rausch JR: Adaptive change in self-concept and well-being during conjugal loss in later life. Int J Aging Hum Dev 2006;63:217-239.
Psychological Well-Being Revisited: Advances in Science and Practice
Psychother Psychosom 2014;83:10-28 DOI: $10.1159 / 000353263$ 
\$3 An JS, Cooney TM: Psychological well-being in mid to late life: the role of generativity development and parent-child relationships across the lifespan. Int J Behav Dev 2006;30: 410-421.

$\$ 94$ Rothrauff T, Cooney TM: The role of generativity in psychological well-being: does it differ for childless adults and parents? J Adult Dev 2008;15:148-159.

$\checkmark 95$ Kotter-Grühn D, Scheibe S, BlanchardFields F, Baltes PB: Developmental emergence and functionality of Sehnsucht (life longings): the sample case of involuntary childlessness in middle-aged women. Psychol Aging 2009;24:634-644.

$\$ 96$ Rothrauff TC, Cooney TM, An JS: Remembered parenting styles and adjustment in middle and late adulthood. J Gerontol B Psychol Sci Soc Sci 2009;64:137-146.

-97 Lavasani MG, Borhanzadeh S, Afzali L, Hejazi E: The relationship between perceived parenting styles and social support with psychological well-being. Procedia Soc Behav Sci 2011;15:1852-1856.

98 Greenfield EA, Marks NF: Linked lives: adult children's problems and their parents' psychological and relational well-being. $J$ Marriage Fam 2006;68:442-454.

$\$ 99$ Schmutte PS, Ryff CD: Success, social comparison, and self-assessment: parents' midlife evaluations of sons, daughters, and self. J Adult Dev 1994;1:109-126.

-100 Rogers CH, Floyd FJ, Seltzer MM, Greenberg J, Hong J: Long-term effects of the death of a child on parents' adjustment in midlife. J Fam Psychol 2008;22:203-211.

101 Pudrovska T: Parenthood, stress, and mental health in late midlife and early old age. Int J Aging Hum Dev 2009;68:127-147.

102 Li LW, Seltzer MM, Greenberg JS: Change in depressive symptoms among daughter caregivers: an 18-month longitudinal study. Psychol Aging 1999;14:206-219.

103 Taylor JL, Greenberg JS, Seltzer MM, Floyd FJ: Siblings of adults with mild intellectual deficits or mental illness: differential life course outcomes. J Fam Psychol 2008;22:905-914.

104 Maier EH, Lachman ME: Consequences of early parental loss and separation for health and well-being in midlife. Int J Behav Dev 2000;24:183-189.

105 Shaw BA, Krause N, Chatters LM, Connell $\mathrm{CM}$, Ingersoll-Dayton B: Emotional support from parents early in life, aging, and health. Psychol Aging 2004;19:4-12.

$\checkmark 106$ Bell LG, Bell DC: Family dynamics in adolescence affect midlife well-being. J Fam Psychol 2005; 19:198-207.

$\checkmark 107$ Bell LD, Bell DC: Positive relationships which support elder health and wellbeing are grounded in midlife/adolescent family. Fam Community Health 2012;35:276-286.

108 Greenfield EA, Marks NF: Identifying experiences of physical and psychological violence in childhood that jeopardize mental health in adulthood. Child Abuse Negl 2010; $34: 161-171$.
109 Lindfors P, Berntsson L, Lundberg U: Total workload as related to psychological wellbeing and symptoms in full-time employed female and male white-collar workers. Int J Behav Med 2006;13:131-137.

110 Strauser DR, Lustig DC, Çıftçı A: Psychological well-being: its relation to work personality, vocational identity, and career thoughts. J Psychol 2008;142:21-35.

111 Carr D: The fulfillment of career dreams at midlife: does it matter for women's mental health? J Health Soc Behav 1997;38:331-344.

112 Johansson G, Huang Q, Lindfors P: A lifespan perspective on women's careers, health, and well-being. Soc Sci Med 2007;65:685697.

113 Srimathi NL, Kiran Kumar SK: Psychological well-being of employed women across different organisations. J Indian Acad Appl Psychol 2010;36:89-95.

114 Ryff CD, Heidrich SM: Experience and wellbeing: explorations on domains of life and how they matter. Int J Behav Dev 1997;20: 193-206.

115 Marks NF: Does it hurt to care? Caregiving, work-family conflict, and midlife well-being. J Marriage Fam 1998;60:951-966.

116 Grzywacz JG: Work-family spillover and health during midlife: is managing conflict everything? Am J Health Promot 2000;14: 236-243.

117 Carr D: The psychological consequences of work-family tradeoffs for three cohorts of men and women. Soc Psychol Q 2002;65: 103-124.

118 Carr D: Psychological well-being across three cohorts: a response to shifting workfamily opportunities and expectations; in Brim OG, Ryff CD, Kessler RC (eds): How Healthy Are We? A National Study of WellBeing at Midlife. Chicago, University of Chicago Press, 2004, pp 452-484.

119 Song J, Marks NF, Han G: Work, family, work-family spillover and mental health among working adults: a comparison of data from national surveys in Korea and the US. J Fam Cult 2007;19:61-92.

120 Son J, Wilson J: Volunteer work and hedonic, eudemonic, and social well-being. Sociol Forum 2012;27:658-681.

121 Choi N, Kim J: The effect of time volunteering and charitable donations in later life on psychological wellbeing. Ageing Soc 2011; 31:590-611.

122 Greenfield EA, Marks N: Formal volunteering as a protective factor for older adults' psychological well-being. J Gerontol B Psychol Sci Soc Sci 2004;59B:S258-S264.

123 Wink P, Dillon M: Religiousness, spirituality, and psychosocial functioning in late adulthood: findings from a longitudinal study. Psychol Aging 2003;18:916-924.

124 Frazier C, Mintz L, Mobley M: A multidimensional look at religious involvement and psychological well-being among urban elderly African Americans. J Couns Psychol 2005;52:583-590.
125 Greenfield EA, Vaillant GE, Marks NF: Do formal religious participation and spiritual perceptions have independent linkages with diverse dimensions of psychological wellbeing? J Health Soc Behav 2009;50:196-212.

126 Heidrich SM, Ryff CD: Physical and mental health in later life: the self-system as mediator. Psychol Aging 1993;8:327-338.

127 Heidrich SM, Ryff CD: The role of social comparison processes in the psychological adaptation of elderly adults. J Gerontol 1993; 48:P127-P136.

128 Heidrich SM, Ryff CD: Health, social comparisons, and psychological well-being: their cross-time relationships. J Adult Dev 1995; 2:173-186.

129 Montpetit MA, Bergeman CS: Dimensions of control: mediational analyses of the stress-health relationship. Pers Individ Dif 2007;43:2237-2248.

130 Keyes CLM: Chronic physical conditions and aging: is mental health a potential protective factor? Ageing Int 2005;30:88-104.

131 Keyes CLM, Grzywacz JG: Health as a complete state: the added value in work performance and healthcare costs. J Occup Environ Med 2005;47:523-532.

132 Andrew MK, Fisk JD, Rockwood K: Psychological well-being in relation to frailty: a frailty identity crisis? Int Psychogeriatr 2012; 24:1347-1353.

133 Kirby SE, Coleman PG, Daley D: Spirituality and well-being in frail and nonfrail older adults. J Gerontol B Psychol Sci Soc Sci 2004; 59B:P123-P129.

134 Heyl V, Wahl H-W: Managing daily life with age-related sensory loss: cognitive resources gain in importance. Psychol Aging 2012;27: 510-521.

135 Hickson L, Allen J, Beswick R, Fulton M, Wolf D, Worrall L, Scarinci N: Relationships between hearing disability, quality of life and well-being in older community-based Australians. Aust NZ J Audiol 2008;30:99-112.

136 Kashubeck-West S, Meyer J: The well-being of women who are late deafened. J Couns Psychol 2008;55:463-472.

137 Moorman SM: Older adults' preferences for independent or delegated end-of-life medical decision making. J Aging Health 2011;23: 135-157.

138 Schleicher H, Alonso C, Shirtcliff EA, Muller DA, Loevinger BL, Coe CL: In the face of pain: the relationship between psychological well-being and disability in women with fibromyalgia. Psychother Psychosom 2005 74:231-239.

139 Mangelli L, Gribbin N, Buchi S, Allard S, Sensky T: Psychological well-being in rheumatoid arthritis: relationship to 'disease' variables and affective disturbance. Psychother Psychosom 2002;71:112-116.

140 Pusswald G, Fleck M, Lehrner J, Haubenberger D, Weber G, Auff E: The 'sense of coherence' and the coping capacity of patients with Parkinson's disease. Int Psychogeriatr 2012;24:1972-1979. 
141 Rafanelli C, Offidani E, Gostoli S, Roncuzzi 155 Pudrovska T: What makes you stronger: age R: Psychological correlates in patients with different levels of hypertension. Psychiatry Res 2012;198:154-160.

142 Guidi J, Rafanelli C, Roncuzzi R, Sirri L, Fava GA: Assessing psychological factors affecting medical conditions: comparison between different proposals. Gen Hosp Psychiatry 2012;35:141-146.

143 Sonino N, Fava GA: A simple instrument for assessing stress in clinical practice. Postgrad Med J 1998;74:408-410.

144 Sonino N, Ruini C, Navarrini C, Ottolini F, Sirri L, Paoletta A, Fallo F, Boscaro M, Fava GA: Psychosocial impairment in patients treated for pituitary disease: a controlled study. Clin Endocrinol 2007;67:719-726.

$\checkmark 145$ Sonino N, Tomba E, Genesia ML, Bertello C, Mulatero P, Veglio F, Fava GA, Fallo F: Psychological assessment of primary aldosteronism: a controlled study. J Clin Endocrinol Metab 2011;96:E878-E883.

146 Cruice M, Worrall L, Hickson L, Murison R: Measuring quality of life: comparing family members' and friends' ratings with those of their aphasic partners. Aphasiology 2005;19: 111-129.

-147 Di Cagno A, Iuliano E, Aquino G, Fiorilli G, Battaglia C, Giombini A, Calcagno G: Psychological well-being and social participation assessment in visually impaired subjects playing torball: a controlled study. Res Dev Disabil 2013;34:1204-1209.

${ }_{148}$ Facchinetti F, Ottolini F, Fazzio M, Rigatelli M, Volpe A: Psychosocial factors associated with preterm uterine contractions. Psychother Psychosom 2007;76:391-394.

149 Gleason CE, Dowling NM, Friedman E, Wharton W, Asthana SM: Using predictors of hormone therapy use to model the healthy user bias: how does healthy user status influence cognitive effects of hormone therapy? Menopause 2012;19:524-533.

150 Holland KD, Holahan CD: The relationship of social support and coping to positive adaptation to breast cancer. Psychol Health 2003;18:15-29.

-151 Carpenter JS, Brockopp DY, Andrykowski MA: Self-transformation as a factor in the self-esteem and well-being of breast cancer survivors. J Adv Nurs 1999;29:1402-1411.

$\checkmark 152$ Cordova MJ, Cunningham LL, Carlson CR, Andrykowski MA: Posttraumatic growth following breast cancer: a controlled comparison study. Health Psychol 2001;20:176185.

153 Costa RV, Pakenham KI: Associations between benefit finding and adjustment outcomes in thyroid cancer. Psychooncology 2012;21:737-744.

154 Costanzo ES, Ryff CD, Singer BH: Psychosocial adjustment among cancer survivors: findings from a national survey of health and well-being. Health Psychol 2009;28:147156. and cohort differences in personal growth after cancer. J Health Soc Behav 2010;51: 260-273.

156 Edwards DJ, Edwards SD, Basson CJ: Psychological well-being and physical self-esteem in sport and exercise. Int J Ment Health Promot 2004;6:25-32.

157 Edwards SD, Ngcobo HSB, Edwards DJ, Palavar K: Exploring the relationship between physical activity, psychological well-being and physical self-perception in different exercise groups. S Afr J Res Sport Phys Educ Recreation 2005;27:1-27.

158 Grzywacz JG, Marks NF: Social inequalities and exercise during adulthood: toward an ecological perspective. J Health Soc Behav 2001;42:202-220.

159 Grzywacz JG, Keyes CLM: Toward health promotion: physical and social behaviors in complete health. Am J Health Behav 2004; 28:99-111.

160 Hamilton NA, Gallagher MW, Preacher KJ, Stevens N, Nelson CA, Karlson C, McCurdy D: Insomnia and well-being. J Consult Clin Psychol 2007;75:939-946.

161 Hamilton NA, Nelson CA, Stevens N, Kitzman H: Sleep and psychological wellbeing. Soc Indic Res 2007;82:147-163.

162 Karlson CW, Gallagher MW, Olson CA, Hamilton NA: Insomnia symptoms and well-being: longitudinal follow-up. Health Psychol 2013;32:311-319.

163 Phelan CH, Love GD, Ryff CD, Brown RL, Heidrich SM: Psychosocial predictors of changing sleep patterns in aging women: a multiple pathway approach. Psychol Aging 2010;25:858-866.

164 Carr DS, Friedman M: Is obesity stigmatizing? Body weight, perceived discrimination and psychological well-being in the United States. J Health Soc Behav 2005;46:244-259.

165 McKinley NM: Women and objectified body consciousness: mothers' and daughters' body experience in cultural, development, and familial context. Dev Psychol 1999;35:760-769.

166 McKinley NM: Resisting body dissatisfaction: fat women who endorse fat acceptance. Body Image 2004;1:213-219.

167 McKinley NM: The developmental and cultural contexts of objectified body consciousness: a longitudinal analysis of two cohorts of women. Dev Psychol 2006;42:679-687.

168 Ryff CD, Singer BH, Love GD: Positive health: connecting well-being with biology. Philos Trans R Soc Lond B Biol Sci 2004;359: 1383-1394.

169 Friedman EM, Hayney M, Love GD, Singer BH, Ryff CD: Plasma interleukin-6 and soluble IL-6 receptors are associated with psychological well-being in aging women. Health Psychol 2007;26:305-313.

170 Lindfors P, Lundberg U: Is low cortisol release an indicator of positive health? Stress Health 2002;18:153-160.
171 Taylor SE, Lerner JS, Sherman DK, Sage RM, McDowell NK: Are self-enhancing cognitions associated with healthy or unhealthy biological profiles? J Pers Soc Psychol 2003; 85:605-615.

172 Hayney MS, Parm D, Love GD, Buck JM, Ryff CD, Singer BH, Muller D: The association between psychosocial factors and vaccine-induced cytokine production. Vaccine 2003;21:2428-2432.

173 Friedman EM, Hayney MS, Love GD, Urry HL, Rosenkranz MA, Davidson RJ, Singer $\mathrm{BH}$, Ryff CD: Social relationships, sleep quality, and interleukin-6 in aging women. Proc Natl Acad Sci USA 2005;102:1875718762.

174 Friedman EM: Sleep quality, social well-being, gender, and inflammation: an integrative analysis in a national sample. Ann NY Acad Sci 2011;1231:23-34.

175 Tsenkova VK, Love GD, Singer BH, Ryff $\mathrm{CD}$ : Socioeconomic status and psychological well-being predict cross-time change in glycosylated hemoglobin in older women without diabetes. Psychosom Med 2007;69: 777-784.

176 Friedman EM, Ryff CD: Living well with medical comorbidities: a biopsychosocial perspective. J Gerontol B Psychol Sci Soc Sci 2012;67:535-544.

177 Boylan JM, Ryff CD: Psychological well-being predicts reduced risk of metabolic syndrome in the MIDUS national sample. Am Psychosom Meet, Miami, 2013.

178 Human LJ, Biesanz JC, Miller GE, Chen E, Lachman ME, Seeman TE: Is change bad? Personality change is associated with poorer psychological health and greater metabolic syndrome in midlife. J Pers 2013;81:249260.

179 Offidani E, Ruini C: Psychobiological correlates of allostatic overload in a healthy population. Brain Behav Immun 2012;26: 284-291.

180 Boyle PA, Buchman AS, Barnes LL, Bennett DA: Effect of a purpose in life on risk of incident Alzheimer disease and mild cognitive impairment in community-dwelling older persons. Arch Gen Psychiatry 2010;67:304310.

181 Boyle PA, Barnes LL, Buchman AS, Bennett DA: Purpose in life is associated with mortality among community-dwelling older persons. Psychosom Med 2009;71:574-579.

182 Boyle PA, Buchman AS, Wilson RS, Yu L, Schneider JA, Bennett DA: Effect of purpose in life on the relation between Alzheimer disease pathologic changes on cognitive function in advanced age. JAMA Psychiatry 2012;69:499-506.

183 Kim ES, Sun JK, Park N, Peterson C: Purpose in life and reduced stroke in older adults: the health and retirement study. J Psychosom Res 2013;74:427-432.
Psychological Well-Being Revisited: Advances in Science and Practice
Psychother Psychosom 2014;83:10-28 DOI: $10.1159 / 000353263$ 
184 Kim E, Sun J, Park N, Kubzansky L, Peterson $\mathrm{C}$ : Purpose in life and reduced risk of myocardial infarction among older US adults with coronary heart disease: a two-year follow-up. J Behav Med 2013;13:124-133.

185 Urry HL, Nitschke JB, Dolski I, Jackson DC, Dalton KM, Mueller CJ, Rosenkranz MA, Ryff CD, Singer BH, Davison RJ: Making a life worth living: neural correlates of wellbeing. Psychol Sci 2004;15:367-372.

186 van Reekum CM, Urry HL, Johnstone T, Thurow ME, Frye CJ, Jackson CA, Schaefer HS, Alexander AL, Davidson RJ: Individual differences in amygdala and ventromedial prefrontal cortex activity are associated with evaluation speed and psychological well-being. J Cogn Neurosci 2007;19:237-248.

187 Heller AS, van Reekum CM, Schaefer SM, Lapate RC, Radler BT, Ryff CD, Davidson RJ: Sustained striatal activity predicts eudaimonic well-being and cortisol output. Psychol Sci, in press.

188 Lewis GJ, Kanai R, Rees G, Bates TC: Neural correlates of the 'good life': eudaimonic wellbeing is associated with insular cortex volume. Soc Cogn Affect Neurosci 2013, E-pub ahead of print.

189 Keyes CLM: The mental health continuum: from languishing to flourishing in life. J Health Soc Behav 2002;43:207-222.

190 Keyes CLM: Mental illness and/or mental health? Investigating axioms of the complete state model of health. J Consult Clin Psychol 2005;73:539-548.

191 Keyes CLM, Dhingra SS, Simoes EJ: Change in level of positive mental health as a predictor of future risk of mental illness. Am J Public Health 2010;100:2366.

192 Valiente C, Provencio M, Espinosa R, Chaves C, Fuentenebro F: Predictors of subjective well-being in patients with paranoid symptoms: is insight necessarily advantageous? Psychiatry Res 2011;189:190-194.

193 Valiente C, Cantero D, Vázquez C, Sanchez Á, Provencio M, Espinosa R: Implicit and explicit self-esteem discrepancies in paranoia and depression. J Abnorm Psychol 2011;120:691-699.

-194 Strauss GP, Sandt AR, Catalano LT, Allen $\mathrm{DN}$ : Negative symptoms and depression predict lower psychological well-being in individuals with schizophrenia. Compr Psychiatry 2012;53:1137-1144.

- 195 Davison TE, McCabe MP, Knight T, Mellor D: Biopsychosocial factors related to depression in aged care residents. J Affect Disord 2012;142:290-296.

$>196$ Feder A, Ahmad S, Lee EJ, Morgan JE, Singh R, Smith BW, Southwick SM, Charney DS: Coping and PTSD symptoms in Pakistani earthquake survivors: purpose in life, religious coping and social support. J Affect Disord 2013;147:156-163.

-197 Rafanelli C, Park SK, Ruini C, Ottolini F, Cazzaro M, Fava GA: Rating well-being and distress. Stress Med 2000;16:55-61.
198 Fava GA, Rafanelli C, Ottolini F, Ruini C, Cazzaro M, Grandi S: Psychological well-being and residual symptoms in remitted patients with panic disorder and agoraphobia. J Affect Disord 2001;65:185-190.

199 Fava GA: Well-being therapy: conceptual and technical issues. Psychother Psychosom 1999;68:171-179.

200 Fava GA, Rafanelli C, Grandi S, Conti S, Belluardo P: Prevention of recurrent depression with cognitive behavioral therapy. Arch Gen Psychiatry 1998;55:816-821.

201 Fava GA, Ruini C, Rafanelli C, Finos L, Conti S, Grandi S: Six-year outcome of cognitive behavior therapy for prevention of recurrent depression. Am J Psychiatry 2004;161:18721876.

202 Ruini C, Fava GA: Well-being therapy for generalized anxiety disorder. J Clin Psychol 2009;65:510-519.

203 Fava GA, Ruini C, Rafanelli C, Finos L, Salmaso L, Mangelli L, Sirigatti S: Well-being therapy of generalized anxiety disorder. Psychother Psychosom 2005;74:26-30.

204 Fava GA, Rafanelli C, Tomba E, Guidi J, Grandi S: The sequential combination of cognitive behavioral treatment and well-being therapy in cyclothymic disorder. Psychother Psychosom 2011;80:136-143.

205 Baldessarini RJ, Vázquez G, Tondo L: Treatment of cyclothymic disorder: commentary. Psychother Psychosom 2011;80:131-135.

206 Fava GA, Ruini C: Development and characteristics of a well-being enhancing psychotherapeutic strategy: well-being therapy. J Behav Ther Exp Psychiatry 2003;34:45-63.

207 Fava GA, Ruini C, Belaise C: The concept of recovery in major depression. Psychol Med 2007;37:307-317.

208 Penn DL, Uzenoff SR, Perkins D, Mueser KT, Hamer R, Waldheter E, Saade S, Cook L: A pilot investigation of the graduated recovery intervention program (GRIP) for first episode psychosis. Schizophr Res 2011;125: 247-256.

209 Hart S, Fonareva I, Merluzzi N, Mohr DC: Treatment for depression and its relationship to improvement in quality of life and psychological well-being in multiple sclerosis patients. Qual Life Res 2005;14:695-703.

210 Hoen B, Thelander M, Worsley J: Improvement in psychological well-being of people with aphasia and their families: evaluation of a community-based programme. Aphasiology 1997;11:681-691.

-211 Pradhan EK, Baumgarten M, Langenberg P, Handwerger B, Gilpin AK, Magyari T, Hockberg MC, Berman BM: Effect of mindfulness-based stress reduction in rheumatoid arthritis patients. Arthritis Care Res 2007;57:1134-1142.

212 Johnson DP, Penn DL, Fredrickson BL, Kring AM, Meyer PS, Catalino LI, Brantley M: A pilot study of loving-kindness meditation for the negative symptoms of schizophrenia. Schizophr Res 2011;129:137-140.
213 Ruini C, Belaise C, Brombin C, Caffo E, Fava GA: Well-being therapy in school settings: a pilot study. Psychother Psychosom 2006;75: 331-336.

214 Ruini C, Ottolini F, Tomba E, Belaise C, Albieri E, Visani D, Offidani E, Caffo E, Fava GA: School intervention for promoting psychological well-being in adolescence. J Behav Ther Exp Psychiatry 2009;40:522-532.

215 Millear P, Liossis P, Shochet IM, Biggs H, Donald M: Being on PAR: outcomes of a pilot trial to improve mental health and wellbeing in the workplace with the Promoting Adult Resilience (PAR) program. Behav Change 2008;25:215-228.

216 Liossis PL, Shochet IM, Millear PM, Biggs H: The Promoting Adult Resilience (PAR) program: the effectiveness of the second, shorter pilot of a workplace prevention program. Behav Change 2009;26:97-112.

217 Hemenover SH: The good, the bad, and the healthy: impacts of emotional disclosure of trauma on resilient self-concept and psychological distress. Pers Soc Psychol Bull 2003; 29:1236-1244.

218 Arkoff A, Meredith GM, Dubanoski JP: Gains in well-being achieved through retrospective proactive life review by independent older women. J Humanist Psychol 2004;44:204-214.

219 Sahdra BK, MacLean KA, Ferrer E, Shaver PR, Rosenberg EL, Jacobs TL, Zanesco AP, King BG, Aichele SR, Bridwell DA, Mangun GR, Lavy S, Wallace BA, Saron CD: Enhanced response inhibition during intensive meditation training predicts improvements in self-reported adaptive socioemotional functioning. Emotion 2011;11:299-312.

220 Jacobs TL, Epel ES, Lin J, Blackburn EH, Wolkowitz OM, Bridwell DA, Zanesco AP, Aichele SR, Sahdra BK, MacLean KA, King BG, Shaver PR, Rosenberg EL, Ferrer E, Wallace BA, Saron CD: Intensive meditation training, immune cell telomerase activity, and psychological mediators. Psychoneuroendocrinology 2011;36:664-681.

221 Shmotkin D: Happiness in the face of adversity: reformulating the dynamic and modular bases of subjective well-being. Rev Gen Psychol 2005;9:291-325.

222 Ryff C, Friedman E, Fuller-Rowell T, Love G, Miyamoto Y, Morozink J, Radler B, Tsenkova V: Varieties of resilience in MIDUS. Soc Personal Psychol Compass 2012;6:792806.

223 Rogers CR: On Becoming a Person. Thousand Oaks, Sage, 1961.

224 Fredrickson BL, Grewen KM, Coffey KA, Algoe SB, Firestine AM, Arevalo JMG, Ma J, Cole SW: A functional genomic perspective on human well-being. Proc Natl Acad Sci 2013;110:13684-13689. 